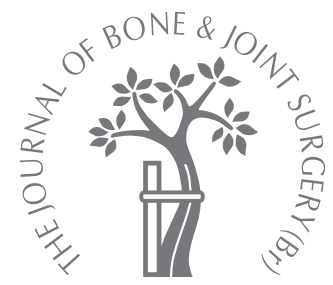

- CASE REPORT

\title{
A modified Gaines procedure for spondyloptosis
}

\section{K. Kalra, S. Kohli, S. Dhar}

From TN Medical and BYL Nair Hospital, Mumbai, India

\footnotetext{
- K. Kalra, MD

New York University Hospital for Joint Diseases, 301 East 17th Street, New York, New York 10003, USA.

S. Kohli, MD, Resident Mount Auburn Hospital, 30 Mount Auburn Street, Cambridge, Massachussetts 02138, USA.

S. Dhar, MS, DNB, Professor Dr D. Y. Patil Medical College, Sector 3, Nerul, Navi Mumbai, PIN 400706, India.

Correspondence should be sent to Dr K. Kalra; e-mail: drkkalra@gmail.com

(C)2010 British Editorial Society of Bone and Joint Surgery doi:10.1302/0301-620X.92B11 $24382 \$ 2.00$

$J$ Bone Joint Surg $[\mathrm{Br}]$ 2010;92-B:1589-91.

Received 3 January 2010;

Accepted after revision 8 June 2010
}

\begin{abstract}
We present an illustrative case using a modification of the Gaines procedure for the surgical management of patients with spondyloptosis. It involves excision of the inferior half of the body of $L 5$ anteriorly combined with posterior reduction and fusion.
\end{abstract}

Grade V spondylolisthesis, or spondyloptosis, is rare. Options for the surgical treatment of patients with this condition include in situ fusion and reduction and instrumentation. ${ }^{1-6}$ The Gaines procedure was first described in 1985 with satisfactory long-term outcomes being reported for 30 patients in 2005. ${ }^{2,3} \mathrm{We}$ describe a modification of this procedure and present an illustrative case report.

\section{Case report}

An 18-year-old male presented with severe pain in the back and legs. He was unable to walk without assistance. The pain had started four years previously and had gradually progressed. He had been treated with a brace and analgesics, but no previous radiographs were available. On examination, he had a crouched gait with a flattened appearance of the buttocks. There was marked tightness of the hamstrings. There was no motor or sensory deficit, but he had experienced some episodes of urinary retention. Electromyography, nerve conduction studies and other urodynamic studies were normal. The radiographs and MR scan are shown in Figures 1 to 3 . We assessed him clinically with the Oswestry Disability Index. ${ }^{7}$ The patient's pre-operative score was 66 . Radiologically we used the slip rotation angle, the slip percentage and Newman's criteria. ${ }^{8}$ These were $26^{\circ}, 100$ and $10+6$ respectively (Table I).

Surgical procedure. The operation was carried out in two stages through anterior and posterior approaches in a single session. The anterior procedure was undertaken with the assistance of a vascular surgeon. The senior author (SD) performed the surgery.

Anterior retroperitoneal approach. The patient was placed supine on the operating table in a $20^{\circ}$ reverse-Trendelenburg position with $15^{\circ}$ of knee flexion. A midline incision from the umbilicus to the pubic symphysis was used. The rectus sheath and muscle were retracted over to the midline. The peritoneum was dissected to approach the retroperitoneal space. The left iliac artery and vein were identified and retracted medially. The segmental vessels were divided laterally. The hypogastric plexus and the ureter were identified and retracted along with the posterior peritoneum. Care was taken to protect the retroperitoneal lymphatics and lumbar sympathetic nerves. The left iliolumbar vein was ligated to avoid traction and injury to it. Blunt dissection and bipolar coagulation were used throughout the procedure. As orientation and visualisation of the entire L5 vertebral body was difficult, fluoroscopy was used and a Kirschner (K)-wire was inserted parallel to the endplate of L5, below the pedicles and directed towards the anteriorsuperior corner of S1 (Fig. 4). Osteotomes were used to resect the L5 vertebra inferior to the Kwire. The L5-S1 disc was identified and curetted to identify the bleeding cancellous bone of the upper end of S1. The posterior longitudinal ligament was visualised. The wound was closed in layers and the patient was turned prone.

Posterior approach. The spine was exposed from L3 to S1 and developed laterally to expose the transverse processes. Pedicle screws were inserted at L3, L4 and S1 guided fluoroscopically. The L4 pedicle screw was the 'reduction' screw with a long stem. After the insertion of pedicle screws, laminectomy of L5 was undertaken. The lamina was loose and could be removed easily. Care was taken to keep the L4-5 facet joints intact. Two $5 \mathrm{~mm}$ rods were templated, cut to length from L3 to S1 and contoured to achieve lordosis after reduction. The rods were then seated onto screws. The inner nuts were placed over the L3 


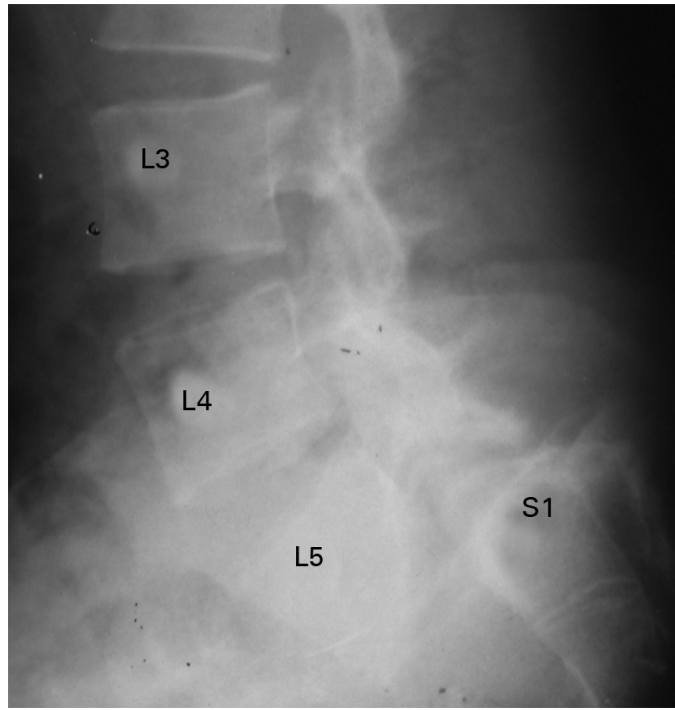

Fig. 1

Lateral radiograph on presentation.

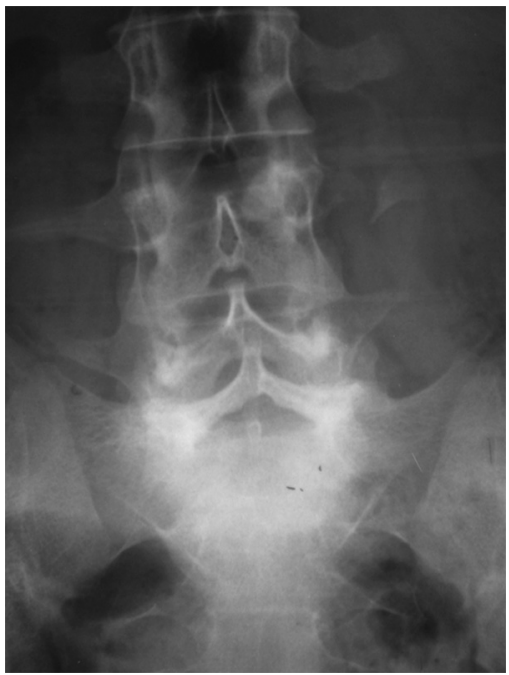

Fig. 2

Anteroposterior radiograph on presentation.

and S1 pedicle screws and tightened over the course of five minutes. This achieved reduction of the deformity. The vertebra was further compressed to achieve adequate lordosis. The outer nuts were then applied and tightened. Bone graft was harvested from the post-iliac crest and applied posteriorly and laterally from L3 to S1 and to the interbody of L5 and S1.

The operation lasted for 5 hours 40 minutes; blood loss was $2300 \mathrm{ml}$. There was no further neurological deficit post-operatively. He was kept overnight in the intensive care unit for monitoring. The wound healed without any complication. A lumbosacral brace was applied and he was allowed to sit up on the second post-operative day. He was

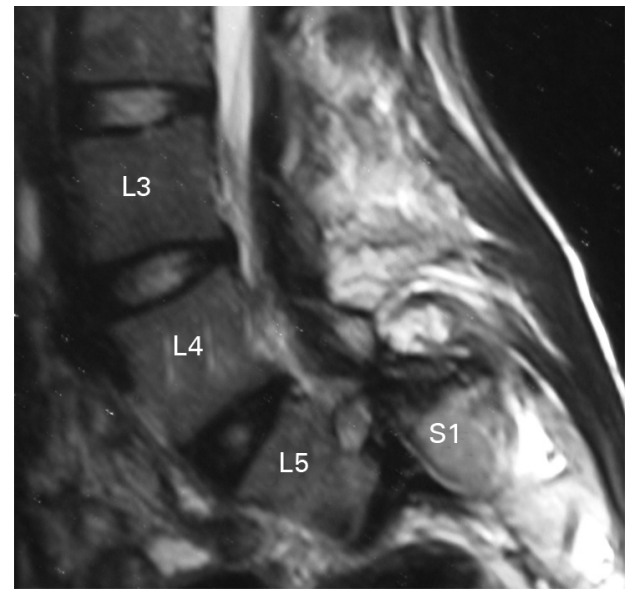

Fig. 3

MR scan when first seen.

Table I. Pre-operative and post-operative findings

\begin{tabular}{|c|c|c|}
\hline & Pre-operative & Post-operative \\
\hline Sagittal rotation angle $\left({ }^{\circ}\right)$ & 26 & $<5$ \\
\hline Slip percentage (\%) & 100 & 0 \\
\hline Modified Newman's criteria & $10+6$ & $0+0$ \\
\hline
\end{tabular}

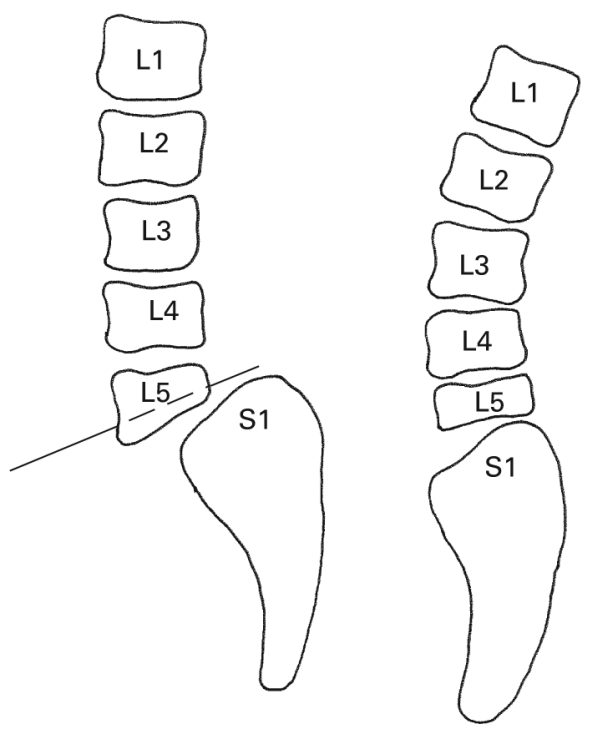

Fig. 4

Illustration describing the osteotomy and the relative 'spinal shortening'.

mobilised in a brace after two weeks and discarded it after three months. Running and lifting heavy weights were restricted for a year.

At follow-up after two years the radiographs showed sound fusion and maintenance of the lordosis (Figs 5 and $6)$. The slip rotation angle improved from $26^{\circ}$ preoperatively to $<5^{\circ}$ post-operatively. The slip percentage 


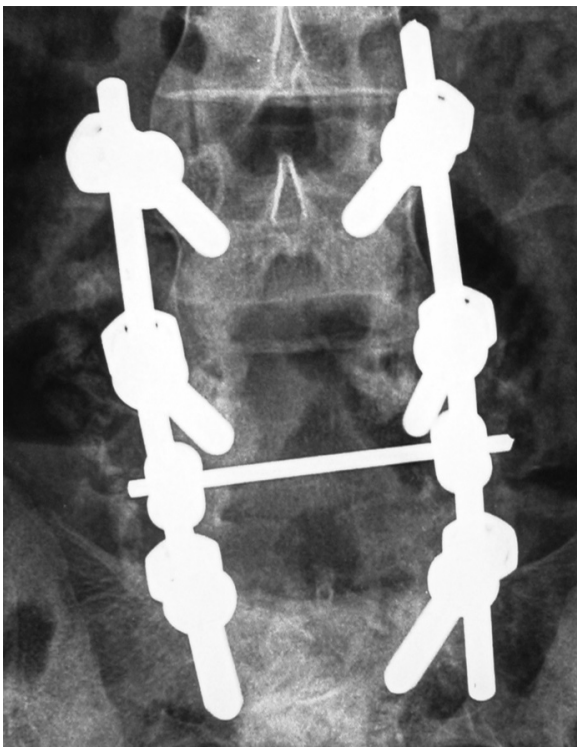

Fig. 5

Post-operative anteroposterior radiograph at two years.

improved from 100 to 0 and the modified Newman's grading improved from $10+6$ to $0+0$. The Oswestry Disability Index was 60 before operation and 6 after two years. The neurological deficit had resolved.

\section{Discussion}

Various methods have been described for the surgical management of patients with a high grade listhesis. Grzegorzewski and Kumar ${ }^{4}$ described in situ fusion for grade III, IV, and $\mathrm{V}$ listhesis and reported satisfactory results. The patients were immobilised for four months in a cast.

Boos et $\mathrm{al}^{5}$ described reduction using posterior instrumentation and reported high rates of nonunion if the posterolateral fusion was not combined with anterior interbody fusion. Gaines and Nichols ${ }^{1}$ described the complete removal of the body of L5 anteriorly followed by reduction of the spondyloptosis posteriorly, with the outcomes ranging from good to excellent. ${ }^{2}$ Our procedure was similar except that we resected only the lower half of L5 anteriorly. This has the following potential advantages. The pedicles of L5 can be used for the reduction screws, which increase the lever arm for the reduction. The procedure prevents excessive crowding of the nerve roots as with complete removal of the vertebral body of L5, by which the L4 and L5 nerve roots may become crowded in the transverse foramen of L4. It also prevents excessive shortening of the spinal cord. In an experimental study on dogs, Kawahara et al $^{9}$ found that shortening of the spinal cord of up to $20 \mathrm{~mm}$ caused changes in the evoked potentials of the spinal cord.

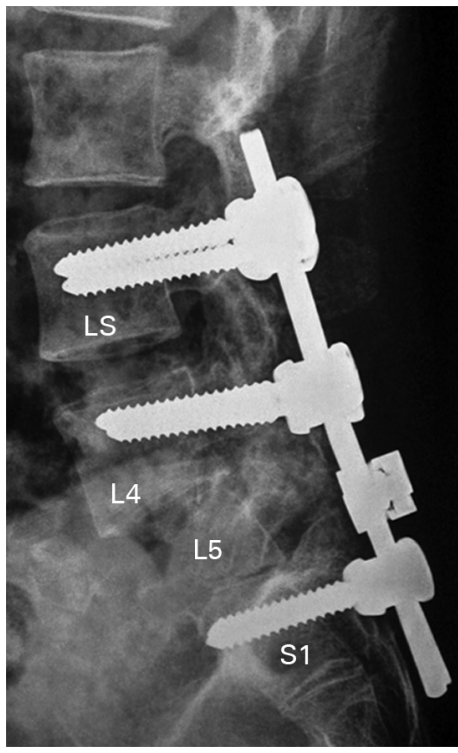

Fig. 6

Post-operative lateral radiograph at two years.

Wild et al ${ }^{10}$ described a similar procedure in a child aged 18 months. This two-stage procedure allowed us to achieve a near normal correction of the sagittal alignment and an excellent restoration of the lordosis, with a high level of patient satisfaction.

No benefits in any form have been received or will be received from a commercial party related directly or indirectly to the subject of this article.

\section{References}

1. Gaines RW, Nichols WK. Treatment of spondyloptosis by two stage L5 vertebrectomy and reduction of L4 onto S1. Spine 1985;10:680-6.

2. Gaines RW. $L 5$ vertebrectomy for the surgical treatment of spondyloptosis: thirty cases in 25 years. Spine 2005;30 (Suppl):66-70.

3. Lehmer SM, Steffee AD, Gaines RW Jr. Treatment of L5-S1 spondyloptosis by staged $\mathrm{L} 5$ resection with reduction and fusion of $\mathrm{L} 4$ onto $\mathrm{S} 1$ (Gaines procedure). Spine 1994;19:1916-25.

4. Grzegorzewski A, Kumar SJ. In situ posterolateral spine arthrodesis for grades III, IV, and V spondylolisthesis in children and adolescents. J Pediatr Orthop 2000;20:50611.

5. Boos N, Marchesi D, Zuber K, Aebi M. Treatment of severe spondylolisthesis by reduction and pedicular fixation: a 4-6-year follow-up study. Spine 1993;18:1655-61.

6. Bradford DS, Tribus CB. Vertebral column resection for the treatment of rigid coronal decompensation. Spine 1997;22:1590-9.

7. Fairbank JC, Pynsent PB. The Oswestry Disability Index. Spine 2000;25:2940-52.

8. DeWald RL. Spondylolisthesis. In Bridwell KH, DeWald RL eds. The textbook of spinal surgery, second ed. Philadelphia: Lippincott-Raven, 1997.

9. Kawahara N, Tomita K, Kobayashi T, et al. Influence of acute shortening on the spinal cord: an experimental study. Spine 2005;30:613-20.

10. Wild A, Jäger M, Werner A, Eulert J, Krauspe R. Treatment of congenital spondyloptosis in an 18-month-old patient with a 10-year follow-up. Spine 2001;26:e5035 